\title{
Abordagem da semântica nos livros didáticos de língua portuguesa em países lusófonos
}

\author{
Sônia Maria NOGUEIRA 『 \\ Universidade Estadual da Região Tocantina do Maranhão (UEMASUL) \\ Daniela Jaqueline Tôrres BARRETO (® \\ Universidade Estadual da Região Tocantina do Maranhão (UEMASUL)
}

\section{○ \\ OPEN ACCESS \\ EDITADO POR \\ - Gonçalo Fernandes (UTAD) \\ - Leonardo Ferreira Kaltner (UFF) \\ - Ronaldo Batista (UPM) \\ AVALIADO POR \\ - Luciano Tocaia (UFMG) \\ - Alessandro Beccari (UNESP) \\ SOBRE OS AUTORES \\ - Sônia Maria Nogueira \\ Conceptualização \\ - Daniela J. Tôrres Barreto \\ Investigação.}

DATAS

- Recebido: 15/09/2021

- Aceito: 20/10/2021

- Publicado: 07/12/2021

COMO CITAR

Nogueira, S. M.; Barreto, D. J. T. (2021). Abordagem da semântica nos livros didáticos de língua portuguesa em países Iusófonos. Revista da Abralin, v. 20, n. 3, p. 586-608, 2021.

\section{RESUMO}

Este artigo pretende verificar aspectos da Semântica em livro didático de Língua Portuguesa de países lusófonos, especificamente do Brasil e de Angola, na década de 2010, uma vez que se reitera a posição em defesa desse instrumento legítimo que auxilia no desenvolvimento do processo ensinoaprendizagem, visto que procura sistematizar e organizar os conhecimentos escolares. Para tanto, os corpora constituem-se das obras: "Para viver juntos: Português", $9^{\circ}$ ano, de Marchetti; Strecker e Cleto (2015), do Ensino Fundamental - anos finais, do Brasil; e "Língua Portuguesa", 9a classe, de Mesquita e Pedro (2014), do $1^{\circ}$ ciclo do Ensino Secundário - Ensino Geral, de Angola; sendo correspondentes em grau de escolaridade. Dessa maneira, será utilizada como metodologia a abordagem documental com análise qualitativa e, em virtude disso, a pesquisa ancora-se nas proposições da Historiografia Linguística: representada por Köerner (1996; 2014), observando-se os princípios de contextualização e imanência; da organização proposta por Swiggers (2010; 2013), Batista (2013), e Batista e Bastos (2020). Estudos em Lusofonia das autoras Bastos e Brito (2013) e Nogueira (2021). O embasamento teórico, inclusive, em Semântica com os autores: Guiraud (1960), Marques (1996), Cançado e Amaral (2017) e Wachowicz (2013). Constatou-se que tanto os gramáticos brasileiros quanto os angolanos propuseram o estudo da teoria Semântica para o ensino-aprendizagem nos materiais didáticos, por meio de atividades específicas sobre aspectos semânticos. 


\section{REVISTA DA ABRALIN}

\section{ABSTRACT}

This article intends to verify aspects of Semantics inserted in Portuguese language textbooks from Portuguese-speaking countries, specifically Brazil and Angola, in the 2010s, once it reiterates the position in defense of this legitimate instrument that helps in the development of the teachinglearning process, since it seeks to systematize and organize school knowledge. Therefore, the corpora consist of the textbooks: "Para viver juntos: Portuguese", 9th grade, by Marchetti; Strecker and Cleto (2015), from elementary school - final years, from Brazil, and "Língua Portuguesa", 9th class, by Mesquita and Gonçalves Pedro (2014), from the 1st cycle of Secondary Education - General Education, from Angola; corresponding in education level. In this way, the documentary approach with qualitative analysis is used as a methodology. Thus, the documentary approach with qualitative analysis will be used as a methodology and, because of that, the research is anchored in the propositions of Linguistic Historiography: represented by Köerner (1996; 2014), observing the principles of contextualization and immancence; in the organization proposed by Swiggers (2010; 2013), Batista (2013), Batista and Bastos (2020). Studies in Lusophony by Bastos and Brito (2013) and Nogueira (2021). The theoretical basis, including, in Semantics with the authors: Guiraud (1960), Marques (1996), Cançado and Amaral (2017) and Wachowicz (2013). It was found that both brazilian and angolan proposed the study of Semantic theory for teaching-learning and teaching materials, through specific activities on semantic aspects.

\section{PALAVRAS-CHAVE}

Semântica da Língua Portuguesa. Livro didático. Historiografia Linguística. Lusofonia.

\section{KEYWORDS}

Portuguese language Semantics. Textbook. Linguistic Historiography. Lusophony.

\section{Introdução}

Este artigo pretende verificar aspectos da Semântica em livro didático (doravante LD), uma vez que se reitera a posição em defesa desse instrumento legítimo que auxilia no desenvolvimento do processo ensino-aprendizagem, porquanto procura sistematizar e organizar os conhecimentos 


\section{REVISTA DA ABRALIN}

escolares. Esta pesquisa trata de manuais didáticos da Língua Portuguesa de países lusófonos, particularmente do Brasil e de Angola. Os corpora são constituídos das obras "Para viver juntos: Português", $9^{\circ}$ ano, de Marchetti; Strecker e Cleto (2015), do Ensino Fundamental - anos finais, do Brasil; e "Língua Portuguesa", 9a classe, de Mesquita e Pedro (2014), do $1^{\circ}$ ciclo do Ensino Secundário Ensino Geral, de Angola, sendo correspondentes em grau de escolaridade. Justifica-se esta seleção em virtude de os LD terem sido adotados, oficialmente, para o uso em escolas dos respectivos países.

Tem-se como procedimentos metodológicos a abordagem documental com análise qualitativa, fundamentada na Historiografia Linguística (doravante HL), representada por Konrad Köerner (1996; 2014) observando-se os princípios de contextualização e imanência; e da organização proposta por Swiggers (2010; 2013), Batista (2013), e Batista e Bastos (2020). Estudos em Lusofonia das autoras Bastos e Brito (2013) e Nogueira (2021). O embasamento teórico, inclusive, em Semântica com os autores: Guiraud (1960), Marques (1996), Cançado e Amaral (2017) e Wachowicz (2013).

Os três aspectos norteadores da análise dos documentos são: a Apresentação, a Organização e o Conteúdo da Semântica. Quanto à estrutura, apresenta quatro seções: Questões historiográficas da língua portuguesa em países lusófonos, Base legal da educação brasileira e da angolana, Estudos Semânticos, e Abordagem da Semântica em livros didáticos, além das considerações finais. Inicia-se, em seguida, a primeira seção: Questões historiográficas da língua portuguesa em países lusófonos.

\section{Questões historiográficas da língua portuguesa em países lusófonos}

Esta seção apresenta estudos teóricos acerca da Historiografia Linguística, Lusofonia e a chegada da Língua Portuguesa no Brasil e em Angola.

\subsection{Historiografia Linguística}

Os países lusófonos, Brasil e Angola, apresentam suas próprias histórias na aquisição e uso da língua portuguesa, até mesmo ao adotá-la como língua oficial. Esta pesquisa procura indicar parâmetros de análises não somente externos "relativos ao contexto de produção de determinada obra ou trabalho", mas também internos "relativos ao conteúdo que trata de descrição e explicação de fenômenos linguísticos", conforme Batista (2013, p. 74).

O objetivo fundamental do historiador, para Swiggers (2013, p. 43, grifo do autor), "é o de reconstruir o ideário linguístico e seu desenvolvimento através da análise de textos situados em seu contexto". Nessa perspectiva, é de suma relevância o conhecimento da história da linguística para que se possa descrever e traçar um paralelo e perceber os avanços ou não do objeto de estudo no decorrer do tempo. 


\section{REVISTA DA ABRALIN}

A palavra "historiografia" seria, morfologicamente, "escrever sobre a história", e "[...] o historiador/historiógrafo é uma figura intelectual que compartilha algo do arqueólogo no exercício de sua função", considerando que ambos iluminam "[...] nosso conhecimento do passado, com suas premissas teóricas e ferramentas metodológicas, interpretando tendo por base as evidências que coletou", afirma Batista (2020, p. 31-32). O historiógrafo vai trabalhar, iniciando com materiais, arquivos, documentos, livros, entre outros, traçando um percurso histórico. Compreende-se que o que ficou no passado, ao se reconstruir, pode trazer entendimentos sobre os estudos da época, por terem sido fatos relevantes e que, de certa forma, impactaram a história daquele corpus que está em análise, seja do passado ou do presente.

Swiggers (2010, p. 2) define que "a historiografia linguística é o estudo interdisciplinar do curso evolutivo do conhecimento linguístico; ela engloba a descrição e a explicação, em termos de fatores intradisciplinares e extradisciplinares". A HL se situa no encontro, ou perpassando pela Linguística, História, Filosofia e Sociologia, descrevendo, explicando e interpretando a história contextualizada das concepções linguísticas. Swiggers (2010), ainda, menciona que o fazer científico da HL deve ser evidenciado:

\footnotetext{
como investigação interdisciplinar, baseada em fundamentos metodológicos sólidos na história da linguística, contribui com insights fundamentais sobre as conquistas (assim como sobre as oportunidades perdidas), sobre os caminhos compensadores (assim como sobre os becos sem saída), sobre os princípios (e pseudoprincípios), as técnicas (e bricolages), os teoremas (e os pressupostos) que marcaram o curso evolucionário do interesse do homem pela metáfora básica que carrega o sentido (e o não-sentido) da vida: a linguagem. (SWIGGERS, 2010, p. 8-9, grifos do autor).
}

A HL é interdisciplinar, traz à investigação organização, padrões metodológicos e epistemológicos. Köerner (2014, p. 16) evidencia que, em certas condições socioeconômicas, "[...] acontecimentos históricos ou situações políticas tiveram frequentemente uma influência considerável na motivação de escrever a história de uma disciplina específica ou na aceitação de um quadro teórico de investigação ou modo de pensamento aparentemente novos". Os acontecimentos históricos influenciam o corpus teórico a ser analisado e, por conseguinte, o fazer historiográfico é relevante para as pesquisas, auxiliando a construir o contexto histórico que cerca o material pesquisado.

A HL proporciona um "[...] guia útil para o tratamento adequado de acontecimentos passados na história das ciências da linguagem" e oferece "[...] uma melhor percepção do rumo para onde as teorias atuais nos podem levar”, de acordo com Köerner (2014, p. 17). Esse é um campo de investigação científica que possibilita um olhar mais atencioso aos fatos passados, lançando luz a teorias atuais.

O uso inadequado da 'metalinguagem' é uma preocupação de Köerner (1996, p. 59-60), tendo em vista "muitos exemplos nos relatos históricos modernos sobre as idéias dos séculos passados, em que idéias, conceitos e procedimentos foram mal compreendidos, deturpados e distorcidos". Os problemas advindos dessa inadequação podem ser solucionados mediante a adoção dos três princípios elaborados por Köerner (1996), o princípio de contextualização, de imanência e de adequação. Ressaltando-se que, nesta pesquisa, não será privilegiado o princípio de adequação. 


\section{REVISTA DA ABRALIN}

O princípio de contextualização, referente à "apresentação de teorias linguísticas propostas em períodos mais antigos, diz respeito ao estabelecimento do 'clima de opinião' geral do período em que as teorias se desenvolveram", indica Köerner (1996, p. 60). Reconhecendo-se que as correntes intelectuais de determinado período se desenvolvem interdependentes e que a situação socioeconômica, política e educacional, também, influenciam as pesquisas e a elaboração das obras. O princípio de imanência aborda sobre o afastamento do historiógrafo de sua "[...] formação linguística individual e dos comprometimentos da Lingüística que lhes são contemporâneos. O quadro geral da teoria sob investigação, assim como a terminologia usada no texto, deve ser definido internamente, e não em referência à doutrina linguística moderna", estabelece Köerner (1996, p. 60). Esse segundo princípio consiste em um pré-requisito indispensável para que haja uma compreensão e interpretação completa do texto linguístico analisado. O terceiro princípio, de adequação, permite "introduzir, ainda que muito cuidadosamente e colocando seu procedimento de forma explícita, aproximações modernas do vocabulário técnico", possibilitando amplo conhecimento do trabalho em análise.

No século XX, a historiografia moderna reviu o "pressuposto objetivo do registro histórico, sempre em busca de uma verdade incontestável" e, com essa atitude, entrou "em cena a consideração de que o historiador/historiógrafo não atua em termos de objetividade, mas impelido (ora mais, ora menos) por sua formação, seus interesses e seus recortes seletivos na busca pela interpretação dos fatos históricos" (BATISTA, 2020, p. 33-34). Para o trabalho do historiógrafo é fundamental ter uma variedade de fontes e não mais um único documento histórico como dono da verdade.

A historiografia linguística é "o campo e a disciplina dos estudos linguísticos que se preocupa em descrever, analisar e interpretar as abordagens (de naturezas diversas, em diferentes materiais, em recortes temporais e sociais diversificados) sobre a linguagem humana e as línguas", relata Batista (2020, p. 38). É um estudo sistemático, analítico, crítico e interpretativo de forma interdisciplinar, porquanto é necessário um leque de saberes para constituir o conhecimento histórico e linguístico do objeto a ser analisado. O trabalho do historiógrafo busca

\footnotetext{
[...] interpretar saberes sobre a linguagem tanto em sua dimensão interna (o que os textos - os documentos históricos - dizem, como dizem, por que o dizem), quanto em sua dimensão externa (o contexto histórico em que esses textos são legitimados como parte de um processo científico e/ou intelectual) (BATISTA, 2020, p. 41).
}

As pesquisas no campo da HL não se prendem, somente, ao estudo das dimensões internas do material em estudo, mas também tratam da dimensão externa, sendo ambos primordiais para a análise. Para a organização do trabalho do historiógrafo, Swiggers (2013, p. 44) defende que existem duas exigências: A primeira exigência é construir um organograma, destacando as "realidades linguísticas"; os "tratamentos e reflexões: história da linguística"; e a "historiografia (descritiva e interpretativa)" mediante "apoio documental: epi-historiografia" e "base de referência teórica: meta-historiografia". E a segunda é a organização "[...] do próprio trabalho historiográfico. Por se tratar de um trabalho sobre textos do passado (e do presente) que servem como base documental". As três fases apresentadas por Swiggers (2013, p. 44) são: heurística, hermenêutica e a executiva. A primeira fase corresponde à leitura das fontes, textos, catalogação e contextualização; a segunda fase aborda a 


\section{REVISTA DA ABRALIN}

interpretação, categorização de forma geral e específica; e a terceira fase trata-se da apresentação dos resultados da investigação.

A realização de trabalhos na HL "[...] se fundamenta (a) na eleição de (temas dentro de) uma área de investigação; (b) no manuseio de um conjunto de conceitos; e (c) em um plano de estudo" (SWIGGERS, 2013, p. 46). Na HL, trabalha-se com seleção de conceitos e termos que auxiliam na organização e reflexão sobre os dados primários. Swiggers (2013) esquematiza em três pontos esses principais conceitos, indicados no Quadro 1:

\begin{tabular}{|c|c|c|}
\hline \multicolumn{3}{|c|}{ PRINCIPAIS CONCEITOS } \\
\hline $\begin{array}{l}\text { I - Pontos/entrelaces de } \\
\text { "ancoragem" (anchoring points): } \\
\text { a) entidades individuais: textos, } \\
\text { autores, usuários. } \\
\text { b) continua: redes, instituições, } \\
\text { escolas, grupos (theory groups), } \\
\text { círculos, sociedades. }\end{array}$ & $\begin{array}{l}\text { II - Linhas de desenvolvimento: } \\
\text { a) rumo evolutivo: mudança, } \\
\text { revolução, } \\
\text { progresso/estagnação/regressão, } \\
\text { conservação/perda/rejeição/recor } \\
\text {-rência, } \\
\text { continuidade/descontinuidade, } \\
\text { inovação, antecipação. } \\
\text { b) relações com o tempo: fonte, } \\
\text { modelo, influência, 'abrangência } \\
\text { referencial' (fr. horizon de } \\
\text { rétrospection), embate de teorias (ing. } \\
\text { theory clash). } \\
\text { c) etapas da evolução: programa de } \\
\text { investigação, tradição (nacional, } \\
\text { étnica, geográfica, modelada, } \\
\text { linguístico-cultural, } \\
\text { cinosura, paradigma. }\end{array}$ & $\begin{array}{l}\text { III - Conteúdos/ } \\
\text { formatos/estratégias. } \\
\text { a) "rotulagem" (labeling): aqui se } \\
\text { põem os termos para referir-se a um } \\
\text { modelo, uma teoria, uma abordagem. } \\
\text { b) em relação a formatos: } \\
\text { b.1) conceitos e princípios teóricos. } \\
\text { b.2) técnicas e estilos de descrição } \\
\text { (por exemplo, Word and Paradigm, } \\
\text { Item and Process, Item and } \\
\text { Arrangement). } \\
\text { b.3) termos T-teoréticos. } \\
\text { c) estratégias: 'deslocamento de } \\
\text { conceitos', transposição, negociação, } \\
\text { (ing. bargaining), empréstimo, } \\
\text { adaptação, recontextualização, } \\
\text { estratégias (retóricas e institucionais) } \\
\text { de promoção ou descarte de teorias. }\end{array}$ \\
\hline
\end{tabular}

\section{QUADRO 1 - Principais conceitos}

Fonte: Elaborado pelas autoras

No Quadro 1, observa-se uma seleção de conceitos e termos que contribuem para a exposição de resultados da investigação historiográfica, sistematizados por Swiggers (2013).

O ensino de língua portuguesa do Brasil e de Angola dialogam, sem dúvida, por meio dos conteúdos do material didático, entendido como "um conjunto amplo de materiais com diferentes configurações e objetivos determinados por fatores pertinentes a cada época histórica", de acordo com Batista e Bastos (2020, p. 53). Busca-se efetuar um estudo comparativo do ensino de conteúdos escolares relacionados à Semântica nestes dois países, por isso convém evidenciar-se a correlação entre a base teórica e a metodologia. Após a HL, aborda-se a Lusofonia.

\subsection{Lusofonia}

Optou-se por abordar a lusofonia, que contempla comunidades com a língua portuguesa oficial, países organizados na Comunidade dos Países de Língua Portuguesa - CPLP, especificamente Angola, pertencente aos Países Africanos de Língua Oficial Portuguesa - PALOP. Cabe ressaltar que os países lusófonos firmam parcerias com vários países e organizações, em diversos níveis: "cultura, educação e fomento, assim como preservação da língua portuguesa, dentre outros", segundo Nogueira (2021, p. 36). 


\section{REVISTA DA ABRALIN}

No contexto das grandes navegações, Portugal difunde sua "língua e cultura, pela atuação de missionários e colonos diante de uma diversidade de povos contatados, espalhados pelos cantos do globo", configurando a constituição de uma 'lusofonia' nos séculos XV e XVI, indicam Bastos e Brito (2013, p. 1). A ideia inicial de lusofonia não contemplava a centralização de Portugal em relação aos demais países de língua oficial portuguesa.

A Língua Portuguesa é herança da colonização e, atualmente, elo de comunicação entre países e povos lusófonos, a qual constitui a organização da sociedade em seus movimentos econômicos, políticos, sociais e educacionais. Lusofonia evoca uma alusão à CPLP, conceituada como "foro multilateral privilegiado para o aprofundamento da amizade mútua, para a concentração político-diplomática e da cooperação entre os seus membros", com a pretensão de agrupar os países de língua oficial portuguesa, com o intuito de uniformizar e difundir a língua, e expandir o intercâmbio cultural entre eles, afirmam Bastos e Brito (2013, p. 2).

A Lusofonia é considerada, por Bastos e Brito (2013, p. 2), "um espaço simbólico linguístico e, sobretudo, cultural, no âmbito da língua portuguesa e das suas variedades que, no plano geo-sóciopolítico, abarca os países que adotam o português como língua", a saber: materna (Portugal e Brasil) e língua oficial (Angola, Cabo Verde, Moçambique, São Tomé e Príncipe, e Guiné-Bissau - os denominados Países Africanos de Língua Oficial Portuguesa (PALOP) - e Timor-Leste, país do sudeste asiático. Em 2005, em uma reunião em Luanda, Angola, com a intenção de lograr a integração dos territórios lusófonos, a CPLP "decidiu que no dia 5 de maio seria comemorado o Dia da Cultura Lusófona pelo mundo". Em 2006, foram admitidos, na categoria de observadores associados: a Guiné Equatorial e as Maurícias. Em 2008, houve a formalização da admissão do Senegal, também, como observador associado, afirma Nogueira (2021, p. 35).

As delimitações das fronteiras políticas não restringem a lusofonia, considerando as "comunidades espalhadas pelo mundo e que constituem a chamada 'diáspora lusa' e as localidades em que, se bem que nomeiem o português como língua de 'uso', na verdade, ela seja minimamente utilizada, como: Macau, Goa, Ceilão, Cochim, Diu, Damão e Málaca", indicam Bastos e Brito (2013, p. 2-3). Essa noção de lusofonia encontra legitimidade quando se entende múltipla e quando nela distintas vozes são reconhecidas e respeitadas.

Pretende-se delinear um percurso da lusofonia nos âmbitos linguístico e territorial, com a intenção de oferecer um painel de abordagem da Semântica em livro didático de língua portuguesa em dois casos pontuais: contexto sul-americano (Brasil) e contexto africano (Angola).

\subsection{A chegada da Língua Portuguesa no Brasil e em Angola}

Em relação à chegada da língua portuguesa no Brasil, deu-se por meio de expedições marítimas vindas de Portugal. Documentos oficiais datam "[...] 09 de março de 1500 como sendo a partida de uma frota de treze navios, liderada por Pedro Álvares Cabral, de Portugal com destino às Índias. Essa frota, na verdade, chega a terras brasileiras em 21 de abril, ancorando em Porto Seguro, Bahia, no dia 


\section{REVISTA DA ABRALIN}

seguinte", relata Balsalobre (2015, p. 30). No início do século XVI, a língua portuguesa chegou ao Brasil, 43 dias após sair de Portugal, por meio das grandes navegações e expedições, à semelhança de Angola.

A colonização do Brasil ocorreu pela ocupação, exploração e invasão do território, visto que a terra era ocupada por indígenas, que povoavam essa terra bem antes dos colonizadores chegarem. Portugal, por meio de "um processo de conferir a nobres determinadas extensões de terra a fim de que eles a administrassem e evitassem invasões", configurava a política de ocupação do território brasileiro, afirma Balsalobre (2015, p. 30). Em 1500, estima-se que havia em torno de mil povos nativos, perfazendo entre dois e quatro milhões de pessoas, e existiam, aproximadamente, mil línguas faladas em território brasileiro. Cabe destacar a língua Tupinambá, a mais falada na costa e "usada como língua de ensino por missões católicas e como comunicação básica entre colonos e nativos", indica Balsalobre (2015, p. 30).

Depois da escravização dos indígenas, os colonos passaram a escravizar os povos africanos, porque, além de gerar impostos e taxas, "as populações africanas submetidas à escravidão detinham um primoroso conhecimento de técnicas agrícolas, de pastoreio e mineração (caso dos povos da Costa da Guiné, do Congo e de Angola), bem como de metalurgia (como os iorubás da costa ocidental africana)", ressalta Balsalobre (2015, p. 31). Os povos africanos eram traficados para trabalharem em outro país, enriquecendo outros povos, usando a produtividade da mão de obra, conhecimentos e a reprodução para crescimento econômico dos colonos.

Em Angola, a língua portuguesa chegou, em 1482, "com as caravelas expedicionárias de Diogo Cão, às quais estavam a caminho marítimo para a Índia e à procura do lendário Império Cristão de Preste João e, por ironia do destino, atracaram nas margens da foz do rio Congo", indica Augusto (2015, p. 60). Na segunda metade do século XV, os tripulantes das caravelas expedicionárias apresentaram a língua portuguesa aos angolanos.

Augusto (2015, p. 60) complementa que, antes da vinda dos colonizadores portugueses para "[...] Angola, os povos estavam organizados em reinos e cada um tinha uma língua que cobria toda a superfície do seu território. A língua era fundamento da identidade de pertença ao grupo étnico e um dos fatores de distinção em relação aos outros reinos". Angola tinha seus reinos com suas respectivas línguas e culturas; e a língua portuguesa chegou como novidade, foi tomando espaço nesses reinos até tornar-se a segunda língua. Balsalobre (2015, p. 70) informa que a "adoção da língua portuguesa pelos países africanos contribuiu para que esse idioma se inserisse no mercado linguístico global como um dos mais importantes e representativos". Com a independência, tendo em vista que a língua tinha um status global e poderia ser uma ferramenta inteligente para lançá-los no mercado mundial, os angolanos permaneceram com a língua portuguesa como oficial.

Zau (2011, p. 106) afirma que, em virtude de a Língua Portuguesa (doravante LP) ser a única língua de escolarização, obteve vantagem sobre as demais línguas porque: "i) a elite aprendeu a ler e escrever em LP, por isso tinha uma dimensão elitista e prestigiante; ii) a literatura, os manuais [...] tudo o que existia estava escrito em língua portuguesa, o que nos leva a inferir que essa língua tinha uma dimensão canônico-literária"; e complementa que "iii) os próprios documentos oficiais dos movimentos de 


\section{REVISTA DA ABRALIN}

libertação nacional estavam escritos em língua portuguesa, quer dizer, a LP tinha uma dimensão oficial e política". Com a língua portuguesa enraizada na cultura, educação, vida, comércio e documentos, não fazia sentido e não seria tão benéfico para adaptação com uma nova língua, por consequência, o mais viável e sensato era continuar com a língua portuguesa como língua oficial.

Em função da semelhante herança do colonialismo português, a língua portuguesa, no Brasil, é oficial e tida como língua materna pela maioria da população brasileira; de tal forma em Angola, a língua portuguesa é oficial, entretanto, convive com outros grupos linguísticos de línguas maternas. A língua portuguesa vem, desde os tempos dos colonizadores, sendo imposta nestes dois países lusófonos como língua oficial, negligenciando as línguas já existentes e faladas. Indica-se, a seguir, a base legal da educação brasileira e da angolana.

\section{Base legal da educação brasileira e da angolana}

No Brasil, duas reformas ocorreram no âmbito educacional durante a ditadura militar e, no ano de 1996, uma nova reforma foi implantada na educação brasileira, com efeito, aconteceu uma reforma geral no sistema educacional, conforme a LDB, Lei nº 9.394/96 (BRASIL, 1996). Com essa nova reformulação, há uma divisão no ensino em educação básica (que contempla a educação infantil: creche, pré-escola; ensino fundamental e ensino médio) e educação superior. A pré-escola continuou como na reforma anterior, todavia, tem a creche que antecede a pré-escola com duração de 4 anos para alunos de 0 a 3 anos, ambas fazem parte da educação infantil. O $1^{\circ}$ grau alterou a nomenclatura para ensino fundamental, o $2^{\circ}$ grau mudou a nomenclatura para ensino médio; no caso do ensino superior, passou a ser educação superior, a nomenclatura é por área escolhida pelo aluno.

A Lei n 11.274/2006 (BRASIL, 2006, p. 1) ampliou o Ensino Fundamental para nove anos de duração, com a matrícula de crianças de seis anos de idade e estabeleceu prazo de implantação, pelos sistemas, até 2010:

Etapa de Ensino
Educação Infantil
Creche
Pré-Escola
Ensino Fundamental
Anos iniciais
Anos finais

$\begin{array}{lc}\text { Faixa Etária Prevista } & \text { Duração } \\ \text { Até cinco anos de idade } & \\ \text { Até três anos de idade } & \\ 4 \text { e } 5 \text { anos de idade } & \\ \text { Até } 14 \text { anos de idade } & 9 \text { anos } \\ \text { De seis a } 10 \text { anos de idade } & 5 \text { anos } \\ \text { De } 11 \text { a } 14 \text { anos de idade } & 4 \text { anos }\end{array}$

Com a implantação do Ensino Fundamental de nove anos ocorreram mudanças na faixa etária, a idade obrigatória de entrada no ensino fundamental passou a ser de seis anos de idade e não mais de sete anos.

Em Angola, no início do século XX, a construção da primeira escola, em Luanda, era destinada ao ensino dos colonos (brancos, "civilizados"). "Em 1963, o governador de Angola, num discurso público designou os Lusíadas como a 'Bíblia do nosso país' para melhor se falar língua portuguesa como elo de comunicação em todo o território de Angola", de acordo com Augusto (2015, p. 67, grifo do 


\section{REVISTA DA ABRALIN}

autor). Na segunda metade do século XX, os angolanos foram obrigados pelas autoridades a terem a obra os Lusíadas, de Camões, como principal obra para aprenderem a falar melhor a língua portuguesa. Os povos angolanos eram obrigados a saberem falar a língua portuguesa para continuarem vivendo em Angola.

Em 2003, o Estatuto Orgânico do Ministério da Educação angolano, na Secção IV Serviços Executivos Centrais, Artigo 16 "Direcção Nacional para o Ensino Geral", estabelece a política educacional por meio do inciso "1. A Direcção Nacional para o Ensino Geral é o serviço encarregue de formular, aplicar e controlar a implementação da política educativa no domínio dos subsistemas do ensino geral e de adultos"; e do inciso 3: "A Direcção Nacional para o Ensino Geral tem a seguinte estrutura: a) Departamento do Ensino Primário e Pré-Primário; b) Departamento do Ensino Secundário; c) Departamento do Ensino Mediatizado; d) Departamento do Ensino de Adultos". Complementando com o Artigo $17^{\circ}$ "Direcção Nacional para o Ensino Técnico-Profissional" e o Artigo $18^{\circ}$ "Direcção Nacional para o Ensino Superior", indica Angola (2003). Percebe-se a preocupação do governo angolano em supervisionar o cumprimento das diretivas do Ministério da educação.

O sistema educacional de Angola passou por uma nova reforma geral, em 2001, ficando dividido em quatro etapas: a primeira etapa, o Ensino Primário, que contempla da $1^{a}$ a $6^{a}$ classes; a segunda etapa, o Ensino Secundário I Ciclo, que abarca da $7^{\mathrm{a}}$ a $9^{\mathrm{a}}$ classes; a terceira etapa, o Ensino Secundário II Ciclo, que compreende da $10^{\mathrm{a}}$ a $12^{\mathrm{a}}$ classes, e a quarta etapa, que trata do Ensino Superior. A Nova Lei de Bases do Sistema de Educação, Lei n. 13/2001, tornou gratuito e democrático o ensino primário, que contempla seis anos de ensino, no qual o aluno inicia a partir dos seis anos e termina aos 11 anos, conforme Liberato (2014).

Os corpora selecionados nesta pesquisa justificam-se por terem sido indicados e adotados nas escolas em seus respectivos países, tanto no Brasil quanto em Angola. Dando prosseguimento, apresenta-se os estudos semânticos.

\section{Estudos Semânticos}

A Semântica é uma ciência que investiga, analisa e explica os sentidos de termos lexicais isolados ou dentro de sentenças, orações e/ou textos. Guiraud (1960, p. 10, tradução nossa) traz a definição de Semântica, mencionando que "a palavra semântica, do grego Semaino, 'significar' (por sua vez, do sema 'signo'), era originalmente o adjetivo correspondente a 'sentido'. Uma mudança semântica é uma mudança de sentido, o valor semântico de uma palavra é o seu sentido"1. Guiraud (1960) menciona a origem da palavra Semântica e do que ela trata: Semântica = algo que significa = signo = sentido. Ele, ainda, enfatiza que "é semântico tudo o que se refere ao significado de um signo de

\footnotetext{
${ }^{1}$ No original: "El vocablo semántico, del griego semaino, "significar" (a su vez de se ma, "signo"), era originalmente el adjetivo correspondiente a "sentido". Un cambio semántico es un cambio de sentido, el valor semântico de una palabra es su sentido" (GUIRAUD, 1960, p. 10).
} 


\section{REVISTA DA ABRALIN}

comunicação, particularmente as palavras"2. Toda vez que se fala de significação, sentido e signo, trata-se de Semântica.

Cançado e Amaral (2017, p. 8), por sua vez, apresentam a definição de Semântica "[...] como uma disciplina ampla, estuda o sentido das palavras e também das sentenças das línguas naturais". Elas trazem a definição de Semântica que estuda o sentido das palavras e sentenças de uma língua e conceituam "a Semântica Lexical como um campo de estudo mais específico da Semântica, ocupa-se primordialmente do sentido das palavras, estabelecendo relações entre propriedades linguísticas e o sentido dos itens lexicais". Nesse sentido, a Semântica Lexical trata do estudo dos fenômenos do léxico.

A Semântica Lexical, ressaltam Cançado e Amaral (2017), trabalha com o conceito de campo lexical ou campo semântico (conjunto de palavras que apresentam uma relação de sentido); com a análise componencial; e com a semântica relacional - sinonímias (palavras de sentido equivalente), hiponímias (palavras com sentido mais específico), antonímias (palavras de sentido oposto), meronímias, homonímias, polissemia -, entre outros.

Wachowicz (2013, p. 153) concorda com o mencionado pelas autoras, afirmando que a Semântica Lexical aborda o estudo do "[...] significado das palavras e sua relação com outros níveis linguísticos outras palavras e sentenças. A Semântica Lexical trata, outrossim, de relações de significado entre sentenças, como o acarretamento e a pressuposição, condicionadas às informações lexicais do verbo". Nessa perspectiva, a Semântica Lexical estuda a relação de sentido do léxico e do léxico inserido nas estruturas sintáticas. Em suma, a Semântica trata do estudo do signo, significado e sentido das palavras. A Semântica Lexical, especificidade da Semântica, aborda os fenômenos semânticos do léxico. Indica-se, em continuidade dos estudos, a abordagem da Semântica em livros didáticos.

\section{Abordagem da Semântica em livros didáticos}

Considerando que a utilização dos manuais didáticos nos países lusófonos seja estabelecida em conformidade com a política educacional, à infraestrutura tecnológica e ao gerenciamento de uma política econômica, o livro didático é "[...] poderosa fonte de conhecimento da história de uma nação, que, por intermédio de [...] leituras, dá a entender que rumos seus governantes escolheram para a educação, desenvolvimento e capacitação intelectual e profissional dos habitantes de um país", afirmam Lajolo e Zilberman (1999, p. 121).

Em relação aos objetivos do livro didático, deixou de ser desenvolvido um estudo sobre ou da língua, o que se almeja é o desenvolvimento do uso da língua, uma vez que são objetivos pragmáticos, a fim de "instrumentalizar o aluno como emissor/receptor de mensagens competente no que tange utilização e compreensão de códigos (verbais e não-verbais)", indica Schröder (2013). O estudo do

\footnotetext{
${ }^{2}$ No original: "Es semântico todo lo que refiere al sentido de un signo de comunicación, particularmente las palavras" (GUIRAUD, 1960, p. 10)
} 


\section{REVISTA DA ABRALIN}

uso da língua ganha mais espaço, abrangendo questões não apenas do léxico em si e suas particularidades, mas ele em relação com o outro, o outro passa a ser relevante no estudo da língua.

Três aspectos na análise dos documentos serão verificados, a saber: a Apresentação, a Organização e o Conteúdo da Semântica, inseridos nos manuais didáticos de Língua Portuguesa de países lusófonos, especificamente, do Brasil e de Angola, sendo correspondentes em grau de escolaridade. Inicia-se com a análise do livro didático do Brasil "Para viver juntos: Português", $9^{\circ}$ ano, de Marchetti; Strecker e Cleto (2015), anos finais - Ensino Fundamental, publicado em São Paulo/Brasil, pela Edições SM, e contém 288 páginas.

Na Figura 1, observa-se a capa da obra

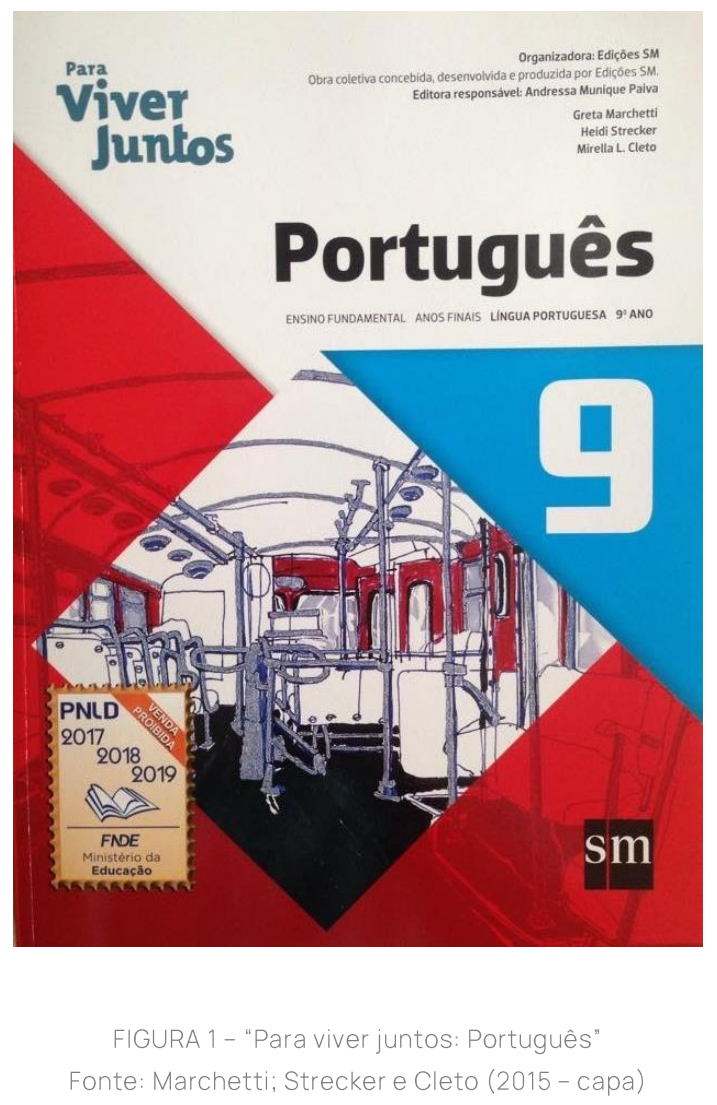

Na capa, além da figura de um ônibus circular usado em zona rural e urbana municipais, apresenta um selo do Ministério da Educação, ratificando que o livro foi aprovado pelo Programa Nacional do Livro Didático (PNLD), válido por três anos: 2017, 2018, 2019, nesse selo, inclusive, consta uma tarja informativa: "venda proibida". Com a chancela do governo brasileiro, pode-se afirmar que Marchetti, Strecker e Cleto (2015) cumprem as leis educacionais, conferindo aos alunos conteúdo pertinente ao desenvolvimento de suas competências e habilidades de leitura e escrita.

Marchetti, Strecker e Cleto (2015, p. 3) inserem uma Apresentação ao aluno, indicando a leitura e análise de vários textos, "e-mails, jornais, revistas, propagandas, rótulos de produtos, manuais de instrução, livros, gibis; ao ouvir programas de rádio e televisão, debates políticos”; além de conversas com 


\section{REVISTA DA ABRALIN}

amigos; possibilitando que, "enfim, em diferentes situações, entramos em contato com múltiplas linguagens e discursos", deixando o leitor consciente de que a linguagem está no nosso dia a dia.

Na sequência, afirmam que a "linguagem é também a ferramenta com a qual expressamos sentimentos, descobertas, queixas, dúvidas e certezas. Se você reparar bem, vai perceber que mesmo nossos mais silenciosos e secretos pensamentos só podem ser formulados porque contamos com esse incrível aparato" (MARCHETTI; STRECKER; CLETO, 2015, p. 3). Há incentivo ao estudo, ao inserirem que: "você lerá e produzirá textos de diferentes gêneros que circulam em diversas esferas sociais. Dessa forma, entrará em contato com um rico universo e poderá expor suas ideias, criar, emocionar-se, argumentar nas mais distintas situações". Ao finalizarem, propõem uma parceria entre professor e aluno mediada pelo livro didático: "esperamos que você descubra as possibilidades oferecidas pelo estudo da Língua Portuguesa. Assim, você poderá ampliar a sua participação no mundo como pessoa mais autônoma, crítica e autora de sua história". Marchetti, Strecker e Cleto (2015) dedicam-se à qualidade do processo ensino-aprendizagem.

Na sequência, o Sumário, contendo nove capítulos, sendo oito deles nomeados por gêneros, e o último capítulo intitulado Revisão. Apresenta-se, no Quadro 2, a estrutura resumida com indicação dos títulos:

\begin{tabular}{|ll|}
\hline Sumário & \\
\hline 1 - Conto Psicológico & 2 - Conto social e conto de amor \\
Leitura 1 & 3 - Crônica esportiva e reportagem \\
Estudo do texto & 4 - Artigo de divulgação científica \\
Produção de texto & 5 - Texto dramático e roteiro \\
Reflexão linguística & 6 - Artigo de opinião \\
Revisão & 7 - Resenha crítica \\
Língua viva & 8 - Anúncio publicitário e anúncio de propaganda \\
Leitura 2 & 9- Revisão \\
Questões da escrita & \\
\hline
\end{tabular}

\section{QUADRO 2 - Estrutura resumida}

Fonte: Elaborado pelas autoras

Foram apresentados alguns itens do Sumário, no Quadro 2, que compõem o Capítulo 1, uma vez que os capítulos de 2 a 8 seguem esta mesma estrutura. Os capítulos apresentam: Leitura 1, Leitura 2, Estudo do texto, Produção de texto, Reflexão linguística, Língua viva, Questões da escrita (sempre na parte da Leitura 2), e Oralidade (nos capítulos 3 e 6, no lugar do tópico Oralidade é utilizado o tópico Interligados).

Os autores dos textos que compõem o livro didático são todos brasileiros, diferente do livro de Angola, no qual identificam-se vários escritores de diferentes países lusófonos. No Quadro 3, quantifica-se atividades e notas de conteúdos sobre Semântica contemplados na obra: 


\section{REVISTA DA ABRALIN}

\begin{tabular}{|c|c|c|c|}
\hline CAPÍTULO & ATIVIDADE & NOTA & SEMÂNTICA \\
\hline \multirow{3}{*}{$\mathbf{1}$} & 1 & 1 & campo semântico \\
\cline { 2 - 4 } & 1 & 1 & Antônimos \\
\cline { 2 - 4 } & 2 & - & Sinônimos \\
\hline $\mathbf{2}$ & 1 & - & Sinônimos \\
\hline \multirow{2}{*}{3} & 1 & - & pronomes relativos e ambiguidade \\
\cline { 2 - 4 } & 2 & - & Sinônimos \\
\hline $\mathbf{4}$ & 1 & - & sem ocorrência \\
\hline $\mathbf{5}$ & - & - & Polissemia \\
\hline $\mathbf{6}$ & 1 & - & Sinônimos \\
\hline & 3 & - & sem ocorrência \\
\hline $\mathbf{7}$ & - & - & sem ocorrência \\
\hline $\mathbf{8}$ & - & - & sem ocorrência \\
\hline $\mathbf{9}$ & - & - & \\
\hline
\end{tabular}

QUADRO 3 - Atividades Semânticas por Capítulos, livro didático do Brasil. Fonte: Elaborado pelas autoras

Conforme o Quadro 3, os Capítulos que apresentam alguma questão, nota e breve conteúdo são o 1, 2, 3, 4 e 6. No geral, os conteúdos semânticos abordados são: Campo semântico, Antônimos, Sinônimos, Ambiguidade e Polissemia. Ao final das atividades "a linguagem do texto", há a teoria em "Anote", especificamente sobre campo semântico: "A escolha de palavras que remetem a um mesmo campo de sentido (quartas-feiras de cinzas/ mortas/ despojos; botão/ rosa) e a repetição de palavras são recursos linguísticos que contribuem para a criação de sentido em uma narrativa. (MARCHETTI; STRECKER; CLETO, 2015, p. 19).

Identifica-se atividade que trata da oposição de sentidos:

3. Releia este trecho do último parágrafo do conto.

[...] numa mistura de carinho, grossura, brincadeira e sensualidade, cobriu meus cabelos já lisos de confete [...]. E eu então, mulherzinha de 8 anos, considerei pelo resto da noite que enfim alguém me havia reconhecido: eu era, sim, uma rosa.

a) No conjunto das quatro palavras destacadas, há dois pares que se opõem. Quais? Que sentido essa oposição cria?

b) Nesse trecho, há outra expressão baseada em uma oposição. De qual expressão se trata? (MARCHETTI; STRECKER; CLETO, 2015, p. 19).

Observa-se a preocupação de Marchetti, Strecker e Cleto (2015, p. 19) em auxiliar o processo ensino-aprendizagem ao inserirem o conceito da antonímia logo após a atividade, no item "Anote", como sendo a "associação de ideias opostas em uma frase pode ser um recurso para expressar os conflitos vividos por uma personagem, por exemplo, aqueles produzidos pela oposição entre seus anseios e a realidade".

Os sinônimos são focalizados no item "reflexão linguística":

1. Leia este trecho de uma notícia. "Governo japonês admite que situação é 'muito grave". Um dia após detectar a presença de plutônio no solo da usina nuclear de Fukushima [...].

e) No primeiro e no último trecho destacado, que verbos poderiam substituir admitir e dizer sem modificar o sentido do texto. (MARCHETTI; STRECKER; CLETO, 2015, p. 59). 


\section{REVISTA DA ABRALIN}

Outra abordagem do uso dos sinônimos encontra-se no item "língua viva": "2. Se Edmundo falasse com autoridades, precisaria adequar sua linguagem. a) Reescreva as frases com as expressões destacadas usando uma expressão mais formal de sentido equivalente e empregue a regência de torcer de acordo com a norma-padrão". (MARCHETTI; STRECKER; CLETO, 2015, p. 203).

Em relação à produção de texto, para a elaboração de "artigo de divulgação científica", Marchetti, Strecker e Cleto (2015, p. 119) auxiliam o aluno no planejamento com a atividade "3. Quanto à linguagem, faça como no artigo lido. a) Em títulos, na linha e nos subtítulos, você pode empregar palavras e expressões de duplo sentido, se considerar que elas vão atrair seu leitor". O estudo da ambiguidade é relevante para o processo ensino-aprendizagem, sendo privilegiado na abordagem de pronomes relativos e a ambiguidade:

\footnotetext{
Dizemos que uma frase ou expressão é ambígua quando ela pode conduzir a mais de uma interpretação. Observe. [Eu procurei o livro e a revista que perdi].

Nessa frase, não se sabe se tanto o livro quanto a revista haviam sido perdidos ou se apenas a revista. A ambiguidade ocorre pois livro e revista são antecedentes do mesmo pronome relativo (que).

[Eu procurei o livro e a revista a qual perdi. (Se perdeu só a revista) / Eu procurei o livro e a revista os quais perdi. (Se perdeu ambos)]. (MARCHETTI; STRECKER; CLETO, 2015, p. 88).
}

Marchetti; Strecker e Cleto (2015, p. 88) complementam a fundamentação teórica em nota: "Em alguns gêneros textuais, como poemas, charges e tiras, a ambiguidade é um importante recurso expressivo intencionalmente utilizado". Eles advertem que, "quando cria dificuldade para a compreensão da mensagem, deve ser evitada".

A reflexão linguística na prática, item fundamental na obra de Marchetti; Strecker e Cleto (2015, p. 190), aborda os variados sentidos da palavra, dependendo do contexto:

2. Leia o trecho a seguir, retirado de um artigo de opinião. ["Dengue: a eliminação depende de você". Já falamos disso no verão do ano passado, mas, devido aos índices alarmantes do país todo em relação às mortes por dengue $[\ldots]$.

e) Dê o significado do verbo bater nestas frases. Atente para a preposição, se houver.

- Estão batendo à porta. Veja quem é.

- $\quad$ Por favor, não bata a porta ao sair: não suporto barulho.

- A escola bateu mais um recorde em atletismo.

- O raio de sol batia na água e brilhava.

- Meu coração bateu muito forte com o resultado da prova.

No capítulo 6, tópico 'Reflexão linguística', segunda questão, item "e", os alunos precisam dar o significado para o verbo polissêmico "bater", de acordo com o emprego dele em cada frase. Sendo assim, "quando se utiliza o termo polissemia, o critério de definição muda do significante para o significado. Assim, palavras polissêmicas, que possuem mais de um significado para o mesmo significante [...]", conforme Pietroforte e Lopes (2003, p. 529). Desse modo, uma palavra que contém vários significados é uma palavra polissêmica.

No estudo gramatical, especificamente na classificação das orações subordinadas adjetivas, as autoras abordam o significado: "2. Leia estes períodos. [I. Os clubes, que tratam o jogador como gado, estão cometendo um excesso. / II. Os clubes que tratam o jogador como gado estão 


\section{REVISTA DA ABRALIN}

cometendo um excesso.] a) As orações destacadas poderiam ser substituídas por um adjetivo de igual significado?" (MARCHETTI; STRECKER; CLETO, 2015, p. 101, grifos das autoras). Logo, essa questão necessita da análise do sentido de dois períodos. No item "a", é questionado se pode ser utilizado um sinônimo para a oração destacada.

A segunda análise refere-se ao livro didático de Angola "Língua Portuguesa", 9ª classe, de Mesquita e Pedro, do $1^{\circ}$ ciclo do Ensino Secundário - Ensino Geral, publicado em Luanda/Angola, Editora das Letras, em 2014, contém 223 páginas. Nessa perspectiva, serão verificados três aspectos na análise: a Apresentação, a Organização e o Conteúdo da Semântica. Na Figura 2, a seguir, verifica-se a capa:

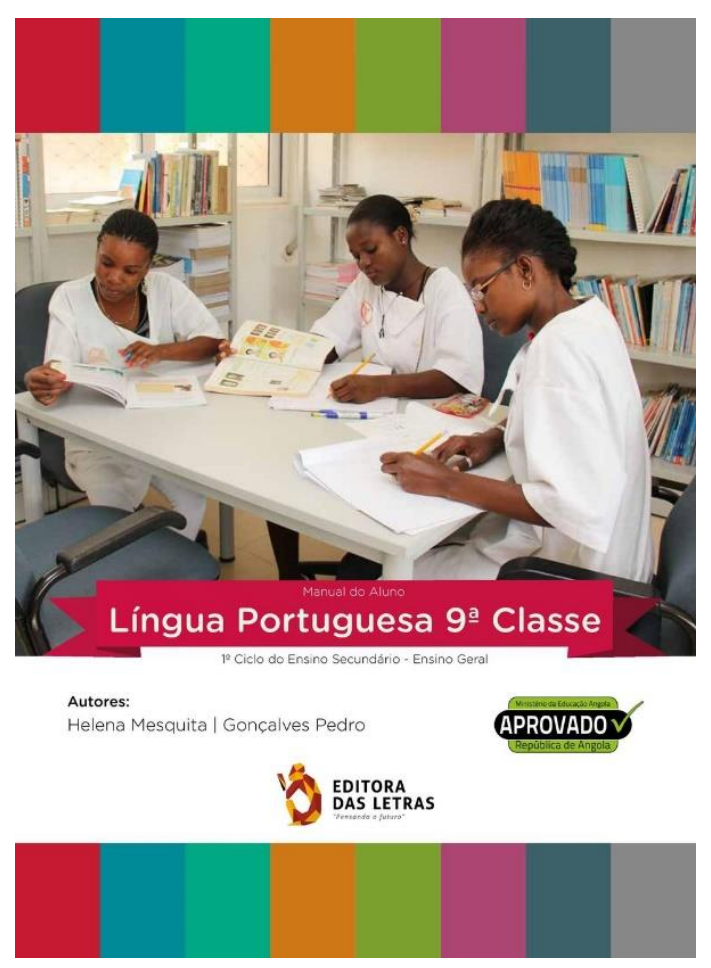

FIGURA 2 - "Língua Portuguesa"

Fonte: Mesquita e Pedro (2014)

Na Figura 2, observa-se que, além de uma foto com três estudantes pesquisando em uma biblioteca, apresenta selo de livro "aprovado", confirmando a chancela pelo Ministério da Educação Angola, da República de Angola.

O livro traz uma apresentação indicada ao Querido Aluno, mostrando empatia com o futuro usuário, em uma breve narrativa da vida estudantil: "Com este Manual da 9. ${ }^{a}$ classe, terminarás mais um ciclo de estudos, o $1 .^{\circ}$ Ciclo do Ensino Secundário. Conheces já muitos dos teus colegas, mas esperam-te inúmeras novidades". Mesquita e Pedro (2014, p. 3) reafirmam a obediência "às linhas programáticas", "atendendo às exigências pedagógico-didáticas", além de não negligenciar "a inovação e o rigor adequados a este nível, no que concerne a uma maior fluência no falar, um maior domínio no escrever, um melhor entendimento no ler e uma melhor compreensão da gramática". 


\section{REVISTA DA ABRALIN}

Em continuidade, eles informam que foi acrescida uma nova tipologia textual, o Texto Argumentativo, "cujas características, como é habitual, te apresentamos ao pormenor". E, finalizam aconselhando que o aluno deverá buscar "[...] saber ser e fazer, individualmente ou em grupo, de modo responsável e criativo, melhorando a relação professor/aluno, aluno/professor e aluno/aluno, para que cada aula seja desenvolvida de forma estruturada e com uma cooperação verdadeira, estreita e compreensiva" (MESQUITA; PEDRO, 2014, p. 3).

Mesquita e Pedro (2014) inserem a apresentação "Caro Professor", manifestando respeito ao professor e aconselhando-o a "ter cuidado para não se afastar dos conteúdos programáticos da $9 .^{\text {a }}$ classe, não descurando os conteúdos apresentados no Apêndice / Bloco Gramatical", e de "trabalhar de forma conveniente a interpretação, recorrendo à investigação, à pesquisa e aos debates realizados na aula, entre outras atividades". Eles instigam o professor à pesquisa, ao afirmarem que, "com base nos exercícios das fichas de leitura apresentadas nas várias tipologias textuais, use a sua criatividade, elabore outros, enriqueça-os, principalmente no que concerne aos textos não trabalhados". Ao concluírem, Mesquita e Pedro (2014, p. 4) contam com a parceria entre professor e alunos, para obterem êxito no uso do livro didático, desejando "bom trabalho, acompanhando e ajudando os seus alunos a ultrapassar todas as dúvidas e os problemas encontrados".

Nas apresentações, é feita a apresentação do manual didático e são dadas orientações, de forma breve, tanto ao aluno quanto ao professor. Os autores destacam que esse é o último livro, do $1^{\circ}$ Ciclo do ensino secundário, com o qual os alunos encerram uma importante etapa do ensino para darem início a outra.

Na sequência do manual é apresentado o Índice, conforme os títulos apresentados, a seguir, no Quadro 4:

\begin{tabular}{|ll|}
\hline Índice & \\
\hline UNIDADE 1 - TEXTO NARRATIVO & UNIDADE 5 - TEXTO EXPLICATIVO \\
UNIDADE 2 - TEXTO DESCRITIVO & UNIDADE 6 - TEXTO INJUNTIVO/APELATIVO \\
UNIDADE 3 - TEXTO POÉTICO/LÍRICO & UNIDADE 7 - TEXTO ARGUMENTATIVO \\
UNIDADE 4 -TEXTO INFORMATIVO & APÊNDICE - BLOCO GRAMATICAL \\
\hline
\end{tabular}

QUADRO 4 - Índice: títulos

Fonte: Elaborado pelas autoras

No Quadro 4, identifica-se a estrutura do manual com sete Unidades, contendo cada uma delas uma introdução prévia, referente a cada tipologia, e um apêndice - bloco gramatical. Sempre após os textos, os autores inserem duas atividades intituladas 'Compreensão do texto' ou 'Exploração do texto' e 'Funcionamento da língua'. Em destaque, no canto inferior direito, a seguinte observação: "Consulte o Bloco Gramatical no final do livro".

Mesquita e Pedro (2014) privilegiam narrativas que abordam o kimbundu, língua bantu é uma das línguas nacionais falada em Angola, "Vou contar sobre o meu cão, mas só em kimbundu". Assim como contos populares de Angola, "Ngana Samba e os Ma-kishi"; e conto de origem nyaneka-humbi, 


\section{REVISTA DA ABRALIN}

denominação usada para designar um dado grupo etnolinguístico, no Sul de Angola, "A Triste Sorte de Katumbo".

Nos textos descritivos, os autores apresentam o texto "Descrição do Carnaval", que ressalta o uso tanto da língua materna quimbundo quanto da língua oficial língua portuguesa: "Aí, em começos de Dezembro, aos sábados à noite e domingos à tarde, estudavam a coreografia e os cantos. Estes, quer em quimbundo, quer em português, quer bilíngue". Em "São Tomé e Príncipe", destaca-se a história deste outro país lusófono. Quanto aos textos informativos, o texto "A Arte Têxtil Angolana" corrobora com o sentimento nacionalista no trecho: "A tecelagem já ganhou estatuto de arte nobre, a par da pintura, escultura, cerâmica e gravura, como suporte decorativo ou sob forma pedagógica, na condição de disciplina curricular da Escola Nacional de Artes Plásticas" (MESQUITA; PEDRO, 2014, p. 50, 106). Observa-se a relevância da abordagem cultural nativa na educação angolana.

O Quadro 5 indica alguns autores e suas nacionalidades, que fazem parte da seleção textual inserida no manual "Língua Portuguesa", 9a classe, de Mesquita e Gonçalves Pedro (2014):

\begin{tabular}{|c|c|c|c|}
\hline AUTOR & PAÍS & AUTOR & PAÍS \\
\hline N’Dá Lussolo & \multirow{15}{*}{ Angola } & Rui Duarte de Carvalho & \multirow{12}{*}{ Portugal } \\
\hline Pepetela & & Gil Vicente & \\
\hline Ermelinda Pereira Xavier & & Agustina Bessa-Luís & \\
\hline Roderick Nehone & & Clara Pinto Correia & \\
\hline Isaquiel Cori & & Ana Maria de Oliveira & \\
\hline José Luís Mendonça & & Sophia de Mello B. Andresen & \\
\hline Rui Augusto & & Faíza Hayat & \\
\hline Geraldo Bessa Victor & & Luís Vaz de Camões & \\
\hline Aires de Almeida Santos & & Fernando Pessoa & \\
\hline Manuel Rui & & Amélia Veiga & \\
\hline Agostinho Neto & & Henrique Abranches & \\
\hline João Maimona & & Maria de Lourdes Brandão & \\
\hline Jorge Gumbe & & Lourenço do Rosário & Moçambique \\
\hline Alda Lara & & Mia Couto & \\
\hline Ernesto Lara Filho & & Inocência Mata & São Tomé e Príncipe \\
\hline Eduardo Neves & \multirow{4}{*}{ Brasil } & Virgílio & Itália \\
\hline Graciliando Ramos & & Desmond Morris & Reino Unido \\
\hline Chico Buarque de Holanda & & Ernest Hemingway & EUA \\
\hline Daniel Cruz & & Kjell Espmark & Suécia \\
\hline
\end{tabular}

QUADRO 5 - Autores e suas nacionalidades.

Fonte: Elaborado pelas autoras

Observa-se, no Quadro 5, autores, predominantemente, de países lusófonos, tais como Brasil, Portugal, São Tomé e Príncipe, Moçambique e Angola. Dessa maneira, percebe-se essa aproximação dos países de mesma língua oficial, por meio do processo ensino-aprendizagem da Língua Portuguesa.

Mesquita e Pedro (2014) inserem questões específicas de Semântica nas atividades presentes em cada Unidade, conforme quantifica-se no Quadro 4: 


\section{REVISTA DA ABRALIN}

\begin{tabular}{|c|c|c|c|c|c|c|}
\hline \multirow{2}{*}{ UNIDADE } & $\begin{array}{c}\text { Compreensão } \\
\text { do texto }\end{array}$ & Semântica & $\begin{array}{c}\text { Exploração } \\
\text { do texto }\end{array}$ & Semântica & $\begin{array}{c}\text { Funcionamento } \\
\text { da língua }\end{array}$ & Semântica \\
\cline { 2 - 7 } & Atividade & Questões & Atividades & Questões & Atividades & Questões \\
\hline $\mathbf{1}$ & 01 & 01 & 08 & 09 & 07 & 01 \\
\hline $\mathbf{2}$ & - & - & 05 & 03 & 04 & 01 \\
\hline $\mathbf{3}$ & - & - & 08 & 03 & 06 & 04 \\
\hline $\mathbf{4}$ & - & - & 08 & 05 & 03 & 01 \\
\hline $\mathbf{5}$ & - & - & 02 & - & 01 & - \\
\hline $\mathbf{6}$ & - & - & 02 & - & 03 & 02 \\
\hline $\mathbf{7}$ & - & - & 05 & 02 & 03 & - \\
\hline
\end{tabular}

QUADRO 6 - Atividades Semânticas por Unidade, livro didático de Angola. Fonte: Elaborado pelas autoras

No Quadro 6, as atividades 'Exploração do texto' são as que mais contemplam questões semânticas. No geral, os conteúdos semânticos abordados nas questões são: sinônimos, o sentido de palavras e expressões, e antônimos. O "Bloco Gramatical" aborda o valor semântico de prefixos e sufixos de origem erudita, e evolução semântica.

Mesquita e Pedro (2014), nas atividades de "Exploração do texto", destacam o estudo dos sinônimos e indica-se alguns exemplos a seguir:

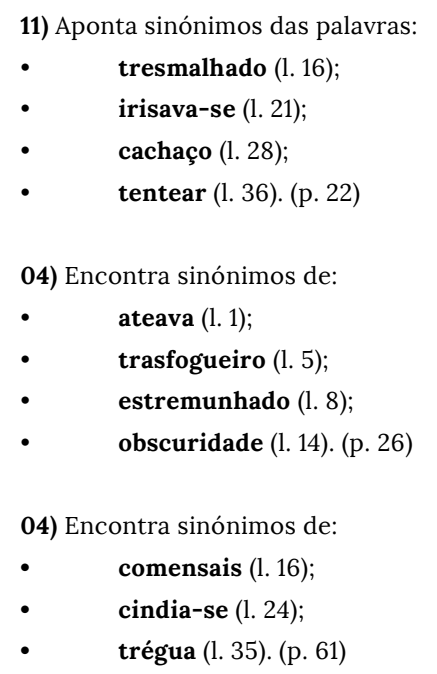

02) Encontra os sinónimos de: flagelados (l. 3), pabulagens (l. 7) e marizeiros (1. 15). (MESQUITA; PEDRO, 2014, p. 22, 26, 61, 63).

Mesquita e Pedro (2014, p. 3) buscam cumprir o objetivo de proporcionar ao aluno "um melhor entendimento no ler e uma melhor compreensão da gramática", incentivando-o a pesquisar sobre sinônimos que contribuem, também, na produção textual.

No texto poético/lírico, em atividade de "Funcionamento da língua", explora-se a morfologia e a sinonímia:

01) «E, pois me já não vedes como vistes, / Não me alegrem verduras deleitosas / Nem águas que correndo alegres vêm.» (vv. 9-11). 


\section{REVISTA DA ABRALIN}

a) Classifica morfologicamente as palavras sublinhadas.

b) Substitui «pois» por uma palavra ou expressão sinónima. (MESQUITA; PEDRO, 2014, p. 82)

Identifica-se a relevância do estudo da semântica, também, na poesia, uma vez que, após as noções de versificação, ocorre a análise tanto morfológica quanto semântica da obra.

Outra abordagem na análise textual é o sentido das palavras, observada nos exemplos de texto narrativo a seguir:

05) Explica o sentido das seguintes frases: a) «O caçador percebeu que tremia incontrolavelmente.» (l. 28). b) «Não tinha coragem de abrir os olhos os olhos; apenas aguardava o ataque da onça.» (1. 31). (MESQUITA; PEDRO, 2014, p. 18)

05) Explica o sentido das seguintes passagens: a) «... a água que se despeja de golpe nos charcos lama-

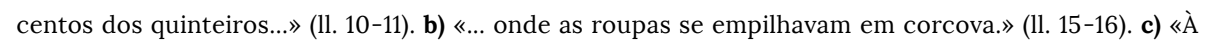
luz de alvorecer, via contra a vidraça o cimo de meda enleado em cruz aureolada com muitos respingos de palha centeia.» (1l.. 16-17). (MESQUITA; PEDRO, 2014, p. 26).

Na indicação das linhas do texto, os autores instigam o aluno a selecionar o sentido da palavra específico para cada contexto de uso. Verifica-se, também, em atividades de texto informativo, "03) Define «travestismo», segundo o sentido que lhe é dado no texto". Diferentemente da atividade de "Funcionamento da língua", que trata de expressões equivalentes: "01) Substitui as seguintes expressões do texto por outras equivalentes, de acordo com o exemplo: tempo de chuva $>$ tempo chuvoso. a) «...inteligência de maldade e destruição...» (1l. 2-3); b) «...turbilhões da atmosfera.» (1. 10)". (MESQUITA; PEDRO, 2014, p. 115, 67).

A teoria semântica é abordada, explicitamente, na atividade de "Funcionamento da língua": "03) O que entendes por palavras parónimas? E homógrafas? a) Dá exemplos de cada uma delas”. Mesquita e Pedro (2014, p. 87) estimulam a pesquisa constante no processo ensino-aprendizagem.

Outro conteúdo semântico em destaque é a antonímia. Marques (1996, p. 73) afirma que os "semas ou componentes mínimos de significado determinam, assim, relações entre os vocábulos da língua. No plano paradigmático, em particular, é possível identificar conjuntos e subconjuntos de itens vocabulares", entre os quais se "estabelecem quatro tipos básicos de relações associativas: oposição, inclusão, participação e associação". A associação por oposição "se estabelece entre vocábulos que têm semas comuns", chamados antônimos, e verifica-se entre eles "relações em que um dos elementos pode ser usado para designar todo o conjunto conceitual em que se opõem". No manual didático angolano, constata-se esta abordagem nas atividades seguintes:

16) Sublinha as antíteses presentes nas frases: a) As ondas do mar inspiravam beleza e horror. b) $O$ rosto pálido está, agora, vermelho de timidez. c) Adormeço e acordo com aquela suave melodia. d) Ele ria com a tristeza estampada no rosto. e) Como viver feliz se vejo a morte à minha frente?

17) Cria frases com base nas antíteses: claro / escuro; beleza / feiura; vida / morte. (MESQUITA; PEDRO, 2014, p. 29). 


\section{REVISTA DA ABRALIN}

Constata-se que Mesquita e Pedro (2014) privilegiam o entrelaçamento da estilística com a semântica em textos narrativos, pois, para resolver as questões 16 e 17, o aluno necessita de conhecimento sobre antônimos.

Quanto ao valor semântico, está presente tanto em atividades de compreensão textual: "02) Faz a caracterização das personagens, apoiando-te no valor semântico dos verbos e de expressões adverbiais"; quanto gramatical: "01) Presta atenção às palavras: quinteiros, refazer, nodosa e vidraça. a) Identifica os afixos que as constituem, assim como a sua origem e o seu valor semântico". (MESQUITA; PEDRO, 2014, p. 26). Os autores diversificam o estudo da semântica, abordando valor semântico de verbos, expressões adverbiais e afixos no processo ensino-aprendizagem indicado ao $9^{\circ}$ ano.

Nas atividades 'Funcionamento da língua', verifica-se uma questão sobre campo semântico, "05) Indica três palavras da família de flor. a) Decompõe-nas nos seus elementos constituintes. b) Refere o significado desses elementos" (MESQUITA; PEDRO, 2014, p. 91). Em virtude desse estudo, os alunos precisam conhecer o campo semântico de "flor" para responderem a questão.

Os provérbios constituem outra seleção textual utilizada por Mesquita e Pedro (2014, p. 37) para o estudo da semântica na obra "Língua Portuguesa", inovando a atividade, conforme segue:

08) Escolhe um dos seguintes provérbios e redige um conto popular que o ilustre:

- Depois de casa roubada, trancas à porta.

- Mais depressa se apanha um mentiroso que um coxo.

- Não te fies em quem uma vez te enganou.

- Quem tudo quer tudo perde.

Os autores interligam o significado original do provérbio e, a partir daí, valorizam o conhecimento de mundo do aluno ao solicitarem a elaboração de conto popular, inclusive nacional. Relevante é a inserção de atividades com textos específicos da cultura angolana, a exemplo de "Cana'ngana":

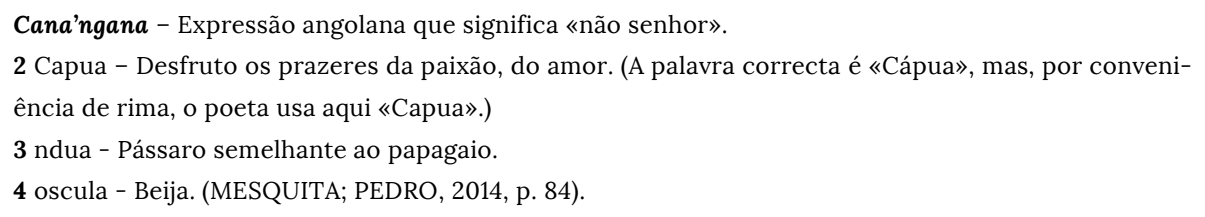

O LD apresenta algumas questões, exclusivamente, sobre aspectos semânticos no decorrer das unidades. E, relacionado à teoria semântica, Mesquita e Pedro (2014) abordam, de modo sutil, o 'Valor Semântico de prefixos e sufixos de origem erudita' e a 'Evolução Semântica', no Apêndice - Bloco gramatical.

Portanto, ambos os livros didáticos abordam questões sobre alguns aspectos semânticos, porém, nenhum dos manuais apresenta uma atividade exclusiva sobre os aspectos semânticos, verificase que o manual de Angola contempla vários textos de autores de países lusófonos, como Portugal, Angola, Brasil, entre outros, enquanto o manual do Brasil privilegia, apenas, autores brasileiros. 


\section{REVISTA DA ABRALIN}

\section{Considerações Finais}

Este estudo buscou verificar o conteúdo de aspectos da Semântica inseridos nos livros didáticos de Língua Portuguesa de países lusófonos, especificamente: do Brasil e de Angola, na década de 2010. Sendo assim, constatou-se que tanto os autores de livro didático brasileiros quanto angolanos propuseram o estudo da teoria Semântica para o ensino-aprendizagem nas suas obras, por meio de atividades sobre aspectos semânticos.

Considera-se relevante compreender e confrontar o ensino de Semântica, em virtude de tratarse de países lusófonos que apresentam uma pretensão de unificação da língua escrita, que compartilham de uma mesma identidade linguística, a língua portuguesa.

\section{REFERÊNCIAS}

ANGOLA. Estatuto Orgânico do Ministério da Educação. Ministério da Educação. Diário da República I Série - № 4717/06/2003. Disponível em: http://www.med.gov.ao/verlegislacao.aspx?id=162. Acesso em: 10 dez. 2019.

AUGUSTO, Moisés Alves. A história do ensino da Língua Portuguesa em Angola. In: Verbum - cadernos de pósgraduação. N.7, p. 60-70, 2015. Disponível em:

https://revistas.pucsp.br/index.php/verbum/article/view/22649/0. Acesso em: 10 set. 2021.

BALSALOBRE, Sabrina Rodrigues Garcia. Brasil, Moçambique e Angola: desvendando relações sociolinguísticas pelo prisma das formas de tratamento. Tese de doutorado. Pós-Graduação em Linguística e Língua Portuguesa da Faculdade de Ciências e Letras - UNESP/Araraquara. p. 346. Araraquara- SP, 2015. Disponível em: https://repositorio.unesp.br/. Acesso em: 27 set. 2019.

BASTOS, Neusa Maria Barbosa; BRITO, Regina Pires de. Cultura e lusofonia: unidade e pluralidade. 2013. Disponível em: https://revistas.pucsp.br/nhengatu/article/view/34176. Acesso em: 27 mar. 2019.

BATISTA, Ronaldo de Oliveira; BASTOS, Neusa Maria Barbosa. Questões em historiografia da linguística: homenagem a Cristina Altman. São Paulo: Pá de Palavra, 2020.

BATISTA, Ronaldo de Oliveira. Introdução à historiografia da linguística. São Paulo: Cortez, 2013.

BATISTA, Ronaldo de Oliveira. História e historiografia da linguística: um mapa de orientação. In: BATISTA, Ronaldo de Oliveira; BASTOS, Neusa Barbosa (orgs.). Questões em historiografia da linguística: homenagem a Cristina Altman. São Paulo: Pá de Palavra, 2020.

BRASIL. LDB. Lei.9.394. 1996. Disponível em: http://portal.mec.gov.br/seesp/arquivos/pdf/lei9394_ldbn1.pdf. Acesso em: 21 jan. 2020.

BRASIL. Lei ${ }^{\circ}$ 11.274, de 6 de fevereiro de 2006. Disponível em: http://www.planalto.gov.br/ccivil_03/_ato2004-2006/2006/lei/111274.htm. Acesso em: 21 jan. 2020.

CANÇADO, Márcia; AMARAL, Luana. Introdução à Semântica Lexical: papéis temáticos, aspecto lexical e decomposição de predicados. Petrópolis, RJ: Vozes, 2017.

GUIRAUD, Pierre. La Semántica. México: Fondo de cultura económica, 1960. 


\section{REVISTA DA ABRALIN}

KÖERNER, Ernst Frideryk Konrad. Questões que persistem em historiografia linguística. In: Revista ANPOLL, nº 2, p. $47-70,1996$

KÖERNER, Ernst Frideryk Konrad. História da linguística. In: Revista Confluência. N. 46. Rio de Janeiro. 1. ${ }^{\circ}$ semestre de 2014. Disponível em: http://llp.bibliopolis.info/confluencia/rc/index.php/rc/issue/view/4. Acesso em: 21 jan. 2020.

LAJOLO, Marisa; ZILBERMAN, Regina. A formação da leitura no Brasil. 3. ed. São Paulo: Ática, 1999.

LIBERATO; Ermelinda. Avanços e retrocessos da educação em Angola. Revista Brasileira de Educação. v. 19 n. 59 out.-dez. 2014

MARCHETTI, Greta; STRECKER, Heidi; CLETO, Mirella L. Para viver juntos: Português. $9^{\circ}$ ano, anos finais, ensino fundamental. 4. ed. São Paulo: Edições SM, 2015.

MARQUES, Maria Helena Duarte. Iniciação à semântica. 3. ed. Rio de Janeiro: Jorge Zahar, 1996.

MESQUITA, Helena; PEDRO, Gonçalves. Língua Portuguesa. $9^{\mathrm{a}}$ classe, $1^{\circ}$ ciclo do Ensino Secundário, Ensino Geral, Luanda/Angola: Editora das Letras, 2014

NOGUEIRA, Sônia Maria. Língua portuguesa: ensino em Portugal e no Brasil, na segunda metade do século XIX, em uma perspectiva historiográfica. São Luís: EDUEMA, 2021.

PIETROFORTE, Antonio Vicente Seraphim; LOPES, Ivã Carlos. Semântica Lexical. In: FIORIN, José Luiz (org.) Introdução à linguística II: princípios de análise. 2. ed. São Paulo: Contexto, 2003. p. 489-538.

SCHRÖDER, Mirian. O ensino de língua portuguesa nas páginas do livro didático. Revista Trama - Volume 9Número 18-2 Semestre de 2013-p. 193-208. Disponível em: http://erevista.unioeste.br/index.php/trama/issue/view/536/showToc. Acesso em: 02 dez. 2019.

SWIGGERS, Pierre. A Historiografia da Língüística: objeto, objetivos, organização.

Confluência. Rio de Janeiro: Editora Lucerna/Liceu Literário Português, n. 44/45. 2013. p. 39-59.

SWIGGERS, Pierre. História e Historiografia da Linguística: Status, Modelos e Classificações. Revista Eutomia. Ano III. Vol. 2. Dez., 2010.

WACHOWICZ, Teresa Cristina. Semântica Lexical. In: FERRAREZI JUNIOR, Celso; BASSO, Renato (Orgs.) Semântica, semânticas: uma introdução. São Paulo: Contexto, 2013.

ZAU, Domingos Gabriel Dele. A Língua Portuguesa em Angola. Um Contributo para o Estudo da sua Nacionalização. Tese de doutorado. Departamento de Letras. p. 204. Covilhã, 2011. Disponível em: https://ubibliorum.ubi.pt/. Acesso em: 02 dez. 2019. 